\title{
Revue analytique des performances agronomiques, nutritionnelles et perspectives de valorisation du riz africain (Oryza glaberrima)
}

\section{REVIEW PAPER}

Claude GNACADJA1,2, Générose VIEIRA-DALODE ${ }^{2}$, Claudine RAZANABOAHIRANA ${ }^{5}$, Paulin AZOKPOTA ${ }^{1,2^{*}}$, Mohamed Mansourou SOUMANOU 3 , Moussa SIE ${ }^{4}$

1 Laboratoire de Biologie Moléculaire et de Formulation Alimentaire ; École de Nutrition, Sciences et Technologies Alimentaires, Faculté des Sciences Agronomiques, Université Abomey Calavi Benin

2 Laboratoire des Sciences des Aliments ; École de Nutrition, Sciences et Technologies Alimentaires, Faculté des Sciences Agronomiques, Université Abomey Calavi Benin

3 Unité de Recherche en Génie Enzymatique et Alimentaire (URGEA), Laboratoire d'Étude et de Recherche en Chimie Appliquée (LERCA), Département de Génie de Technologie Alimentaire, École Polytechnique d'AbomeyCalavi, Université d'Abomey- Calavi Bénin.

4 Centre du riz pour l'Afrique (AfricaRice), Madagascar

5 Centre National de Recherche pour le Développement Rural - (FOFIFA), Madagascar

Auteur correspondant: Paulin AZOKPOTA: Tél: 00229972212 49; Email : azokpotap@yahoo.fr, paulin.azokpota@fsa.uac.bj

Original submitted in on $12^{\text {th }}$ October 2017. Published online at www.m.elewa.org on $28^{\text {th }}$ February 2018 https://dx.doi.org/10.4314/iab.v122i1.1

\section{RÉSUMÉ}

Objectifs: Le riz africain a été utilisé pendant longtemps dans les systèmes d'amélioration variétale. Malheureusement, il est en voie de disparition. Cette revue analytique vise principalement à faire une synthèse des travaux réalisés sur le riz africain afin de définir des perspectives de recherche pour sa valorisation.

Méthodologie et résultats : Elle est réalisée à partir d'une documentation axée sur la pertinence des articles. Une centaine d'articles scientifiques parus dans des revues indexées et/ou à facteur d'impact à diffusion internationale ont été exploités. Les résultats montrent que le riz en générale a une grande importance socioéconomique et alimentaire. Les potentialités agronomiques et génétiques du riz africain font de lui un important patrimoine agricole pour faire face aux défis de l'agriculture en Afrique et à l'amélioration variétale. Ses performances avec les contraintes liées à sa compétitivité suscitent un élan de recherche en vue de sa valorisation.

Conclusion et applications des résultats : Le riz africain constitue un véritable réservoir de gènes de résistance ou de tolérance à de nombreux stress environnementaux et présente également une diversité variétale lui permettant de s'adapter à plusieurs types d'habitat. II ressort de cette revue analytique qu'une perspective de recherche axée sur l'exploitation des atouts du riz africain permettrait de booster la production rizicole en Afrique et de limiter sa dépendance en riz importé. Ce plan de recherche offrira une visibilité au riz africain et contribuera à la souveraineté alimentaire en Afrique.

Mots clés : Oryza glaberrima, Potentiels, Amélioration, Valorisation. 
African rice (Oryza glaberrima), alternative for imported rice?

Analytical review of agronomic and nutritional performance and prospects for valorization

\begin{abstract}
Objectives : For a long time African rice (Oryza glaberrima) was used in rice varietal improvement technical systems. Unfortunately, the African species is on the brink of extinction. This analytical review aims at summarising the work done about African rice in order to define research perspectives for its valorisation. Méthodology and results : It is based on documentary research focuses on the relevance of the articles. In total, some 100 scientific articles appeared in indexed journals and / or with an international impact factor have been exploited. The results show rice, generally has socio economic and food importance. The agronomic performance of African rice (Oryza glaberrima) makes it an important agricultural heritage for the challenges of agriculture in Africa and varietal improvement. Its genetic potential and its competitiveness constraints arouses research prospects for its valorisation.

Conclusions and application of findings : African rice is a reservoir of genes for resistance or tolerance to many environmental stresses and it also has varietal diversity allowing to adapt to several soil types. From the analysis of its results, a scientific research perspective focusing on the full exploitation of the assets of African rice would boost rice production in Africa and limit its dependence on imported rice. This research plan will provide visibility to African rice on a global scale and in the balance of food sovereignty in Africa.
\end{abstract}

Keywords : Oryza glaberrima, Potentials, Improvement, Valorization.

\section{INTRODUCTION}

Le riz constitue la source d'alimentation pour environ $50 \%$ de la population mondiale (Nguetta et al., 2006). La filière rizicole en Afrique constitue l'un des secteurs clés pour la sécurité alimentaire qui connait encore de réels problèmes pour son développement ; notamment, la méconnaissance de la qualité des variétés de riz africain (Oryza glaberrima) et leur non adoption liée aux soupçons portés sur leur valeur nutritionnelle (Lançon et al. 2004). L'apparition de l'espèce asiatique de riz dans l'espace africain en général, et dans la sous-région ouest-africaine en particulier a contribué à faire reculer la culture de Oryza glaberrima (Africarice, 2010). En effet l'espèce africaine a régressé devant les variétés de Oryza sativa en raison d'abord de sa faible productivité par à l'espèce asiatique; ensuite quelques préjugés colonialistes expliquent la régression de Oryza glaberrima. La création et l'adoption rapide des nouvelles variétés de riz grâce aux progrès réalisés dans le processus de la sélection variétale ont relativement entraîné la disparition des variétés traditionnelles et locales (Africarice, 2010). Les variétés africaines qui étaient cultivées depuis très longtemps, bien avant l'introduction des variétés asiatiques, sont bien conservées et toujours cultivées dans certaines régions en Afrique de l'ouest. En dépit de ces niches conservatrices, le déclin de la culture des variétés locales est toujours au cœur des problèmes de la riziculture. Toutefois, les variétés locales constituent un grand réservoir de potentiels de résistance utiles pour les programmes d'amélioration génétique des plantes (Sarla et Swamy, 2005 ; Futakuchi et Sié, 2009). Pour la valorisation du riz africain (O. glaberrima), en vue de susciter l'espoir d'une production massive notamment en Afrique Subsaharienne en quête d'une souveraineté alimentaire, il est important que la recherche soit orientée vers le développement de ses variétés à travers l'amélioration de leur productivité et de leur qualité nutritionnelle. De nombreux travaux ont déjà été réalisés dans ce sens sans pour autant atteindre pleinement ces objectifs. II importe maintenant de réaliser un état des lieux de ces travaux afin de donner une nouvelle orientation à la recherche sur le riz africain. La présente revue vise principalement à faire un récapitulatif des travaux antérieur sur le riz africain à partir duquel de nouveaux objectifs de recherche pourraient être définis. De façon spécifique, il s'agit : 
- $\quad$ Réaliser un état des lieux sur la production du riz au plan régional et international; et son importance socio-économique et nutritionnelle,

- $\quad$ Décrire les potentiels du riz africain et les contraintes liées à sa valorisation,

\section{MÉTHODOLOGIE}

La rédaction de cette revue de synthèse a fait objet d'une recherche bibliographique dans plusieurs bases de données à savoir : Mémoires online, Agora, Hal. Archives ouvertes, Theses.fr, ScienceDirect et également dans les archives d'articles du Centre de Riz pour l'Afrique (AfricaRice). Au total, une centaine d'articles scientifiques

\section{RÉSULTATS ET DISCUSSION}

Valeur nutritionnelle et importance du riz dans l'alimentation humaine : Le riz constitue la première céréale mondiale destinée à l'alimentation humaine en termes de production et représente l'aliment de base d'une population de plus de trois milliards de personnes, ce qui équivaut à plus de la moitié de la population mondiale (Cantral et Reeves, 2002). La consommation annuelle du riz par habitant peut être très importante dans les pays grands consommateurs d'Asie ou d'Afrique. En effet, aux Philippines, à Madagascar ou en Guinée, la consommation par tête dépasse les $100 \mathrm{~kg} / \mathrm{an}$. Au-delà d'être source d'alimentation pour environ $50 \%$ de la population mondiale, le riz représente la principale source de protéines pour plus de 2,5 milliards de personnes dans les pays en voie de développement (Gallais et Bannerot, 1992 ; Nguetta et al., 2006). II se distingue des autres céréales par sa teneur élevée en glutélines (solubles dans les bases diluées) et faibles en prolamines (solubles
Projeter des perspectives de recherche en vue de la valorisation du riz africain.

parus dans des revues indexées et/ou à facteur d'impact à diffusion internationale ont été exploités. En outre, des informations pertinentes sur le riz provenant des rapports techniques et des communications scientifiques ont été également collectées.

dans les solutions alcooliques) (Juliano, 1994 ; Laignelet, 1998 ;). Sur le plan nutritionnel et d'une manière générale, le riz présente une large gamme d'éléments nutritifs (Tableau 1). En Afrique de l'ouest et en dehors du Nigeria, la consommation régionale de riz se situe à la première place avec $27 \%$ sur l'ensemble des céréales consommées (Mendezdelvillar et al., 2011). L'exploitation des données issues des enquêtes réalisées par le PAM (Programme Alimentaire Mondiale) et ses partenaires au Bénin (2009), au Libéria, en Guinée-Bissau et au Sénégal (2010) permet de situer la place du riz dans la sécurité alimentaire familiale de ces pays (Figures 1 et 2). Contrairement à ce que l'on pourrait penser, le riz ne semble pas être un aliment spécifiquement consommé par les ménages urbains. La contribution du riz à la consommation alimentaire globale est particulièrement forte pour les ménages en situation d'insécurité alimentaire, notamment des milieux urbains (PAM, 2009). 
Gnacadja et al., J. Appl. Biosci. 2018 Revue analytique des performances agronomiques, nutritionnelles et perspectives de valorisation du riz africain (Oryza glaberrima)

Tableau 1 : Teneurs en éléments nutritifs évaluées dans $100 \mathrm{~g}$ de riz cuit

\begin{tabular}{|c|c|c|}
\hline \multicolumn{2}{|l|}{ Nom des constituants (unités) } & Teneurs moyennes \\
\hline \multicolumn{2}{|l|}{ Énergie (Kcal) } & 130 \\
\hline \multicolumn{2}{|l|}{ Eau $(\mathrm{g})$} & 70,4 \\
\hline \multirow{5}{*}{ Substances nutritives } & Protéines (g) & 2,8 \\
\hline & Glucides (g) & 28,8 \\
\hline & Sucres $(\mathrm{g})$ & 0,11 \\
\hline & Amidon $(\mathrm{g})$ & 28,7 \\
\hline & Lipides (g) & 0,37 \\
\hline \multirow{3}{*}{ Acides gras } & Saturés (g) & 0,07 \\
\hline & Monoinsaturés (g) & 0,07 \\
\hline & Polyinsaturés (g) & 0,09 \\
\hline \multicolumn{2}{|l|}{ Fibres alimentaires (g) } & 0,9 \\
\hline \multirow{7}{*}{ Minéraux et oligoéléments } & Sodium (mg) & 2 \\
\hline & Magnésium (mg) & 9 \\
\hline & Phosphore (mg) & 55 \\
\hline & Potassium (mg) & 56 \\
\hline & Calcium (mg) & 19 \\
\hline & Manganèse (mg) & 0,35 \\
\hline & Sélénium $(\mu \mathrm{g})$ & 8,2 \\
\hline \multirow[t]{3}{*}{ Métaux } & Fer total (mg) & 0,24 \\
\hline & Cuivre (mg) & 0,07 \\
\hline & Zinc (mg) & 0,37 \\
\hline \multicolumn{2}{|l|}{ lode $(\mu \mathrm{g})$} & 5 \\
\hline \multicolumn{2}{|l|}{ Rétinol $(\mu \mathrm{g})$} & 0 \\
\hline \multicolumn{2}{|l|}{ Bêta-carotène $(\mu \mathrm{g})$} & 0 \\
\hline \multirow{9}{*}{ Les vitamines } & B1 ou Thiamine (mg) & 0,07 \\
\hline & B2 ou Riboflavine (mg) & 0,01 \\
\hline & B3 ou PP ou Niacine (mg) & 2,31 \\
\hline & B5 ou Acide pantothénique (mg) & 0,32 \\
\hline & B6 ou Pyridoxine $(\mathrm{mg})$ & 0,15 \\
\hline & B9 ou Folates totaux $(\mu \mathrm{g})$ & 4 \\
\hline & B12 ou Cobalamines $(\mu \mathrm{q})$ & 0 \\
\hline & $\mathrm{C}(\mathrm{mg})$ & 0 \\
\hline & $\mathrm{D}(\mu \mathrm{g})$ & 0 \\
\hline \multicolumn{2}{|c|}{ Activité vitaminique E (=alpha-tocophérol) (mg) } & 0 \\
\hline
\end{tabular}

Source : (ANSES, 2008) 


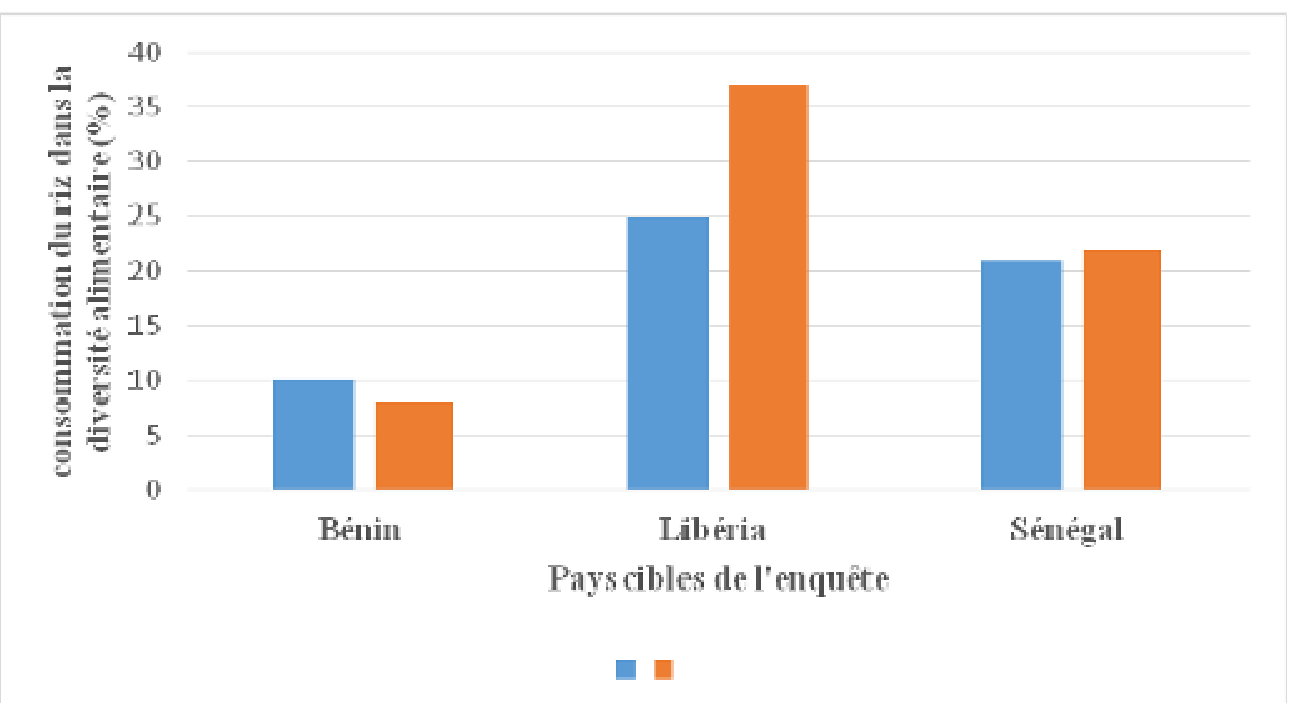

Figure 1: Part du riz dans la consommation des ménages, milieu rural et urbain (\% du riz dans le score de diversité alimentaire).

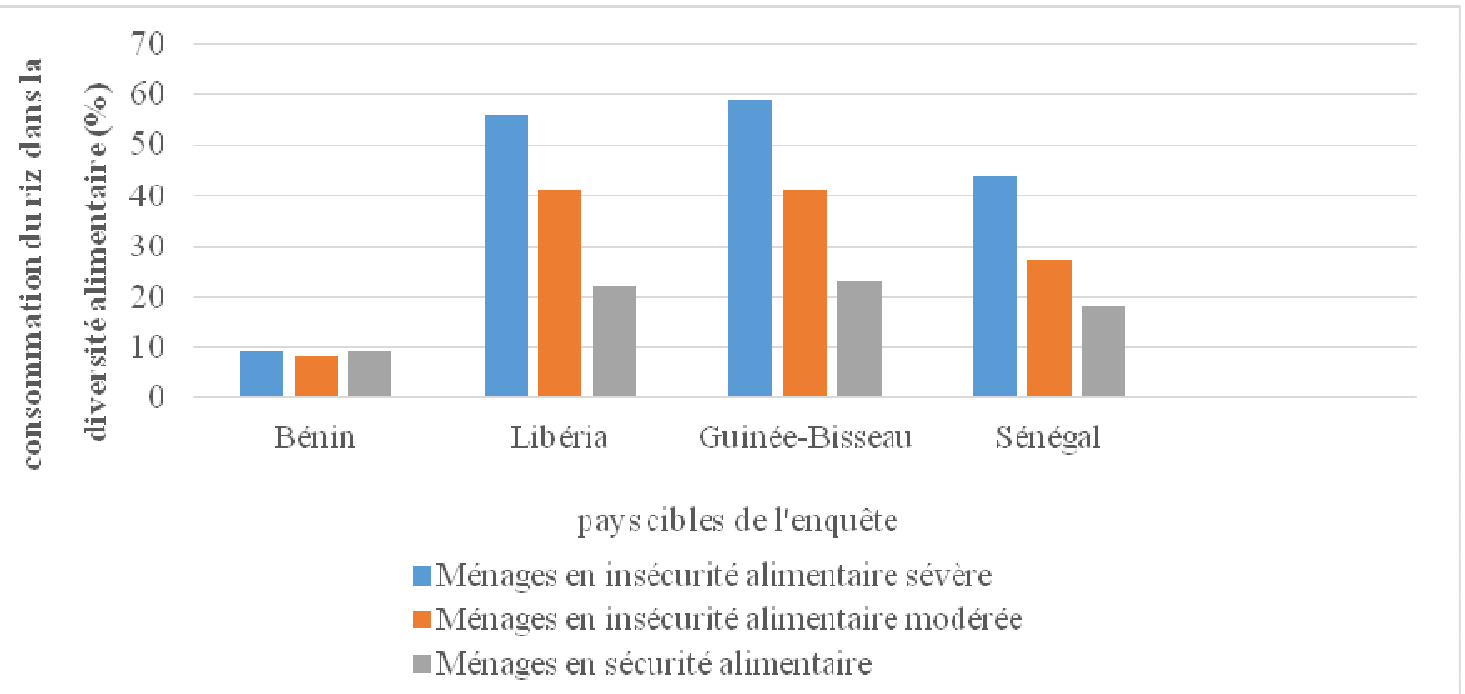

Figure 2 : Part du riz dans la consommation des ménages, par niveau d'insécurité alimentaire.

Figures 1 et 2, Source : (PAM, 2009).

Importance socio-économiques du riz : Les récentes données de la FAO révèlent que, contrairement à 2016 où les prix internationaux du riz ont connu leur plus bas niveau, les premiers mois de 2017 ont été déjà caractérisés par la hausse des prix, surtout pour les variétés parfumées. Cette observation relève de l'Indice FAO des prix du riz (2002-2004=100), qui s'est établi en moyenne à 198 points à la mi-avril, en hausse de 6\% par rapport à décembre 2016 (FAO, 2017). Au plan régional, le riz est une des cultures d'intérêt, hautement stratégique et présente un potentiel de rentabilité considérable à travers le marché régional (Balasubramanian et al.,
2007). Son importance et son intérêt stratégiques viennent, non seulement, du fait que l'activité rizicole emploie plus de 20 millions de d'acteurs des zones rurales et constitue (directement ou indirectement) le moyen de subsistance pour plus de 100 millions de personnes (Balasubramanian et al., 2007), mais aussi du fait que la région ouest-africaine connaît une forte saignée de devises occasionnée par les importations massives de riz (Zoundi et al., 2005). Le riz produit en Afrique est, pour la grande partie, autoconsommé (Sié, 1991). Une infime partie fait l'objet de commercialisation sur les marchés internationaux. Malgré les nombreuses 
charges liées à sa production, le riz au Togo par exemple, est la culture la plus rentable parmi les céréales cultivées (Aboa et al., 2007). En dépit des efforts consentis par les états ouest-africains et les subventions accordées au sous-secteur dans certains pays comme le Sénégal, le développement de cette culture demeure lié à la production et à la politique commerciale des pays asiatiques.
Production du riz au plan régional et international Différentes espèces de riz produits : Le riz (Oryza spp.) (Photo 1) est une plante de l'embranchement des Spermaphytes, de la classe des monocotylédones et de l'ordre des Cyperales. Le genre Oryza fait partie de la famille des Poaceae, de la sous-famille des Panicoïdeae et de la tribu des Oryzeae (Sié et al., 2009).

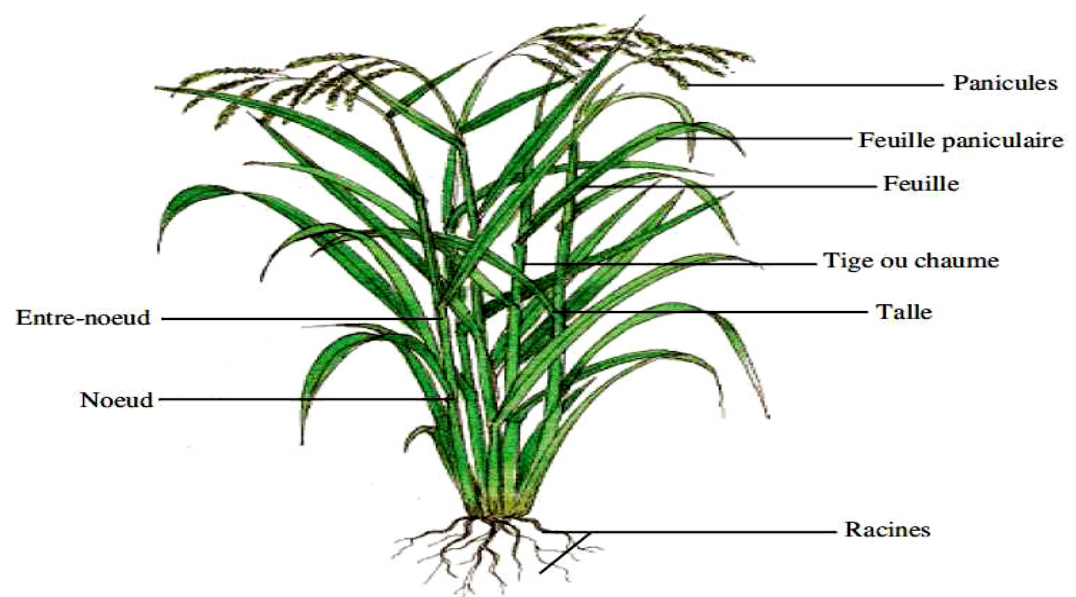

Photo 1 : Plant de riz.

Source : (Sié et al. 2009).

II regroupe environ 23 espèces dont principalement deux sont cultivées : $O$. sativa (d'origine asiatique) et $O$. glaberima (d'origine africaine) (Megan et Mccouch, 2007). 0 . sativa est l'espèce de riz la plus cultivée partout ailleurs dans le monde (Juliano et al., 1964). Les riz sauvages et cultivés appartiennent au genre botanique Oryza. Seul le groupe Sativa est actuellement considéré comme groupe à l'origine de la domestication des riz. La forme asiatique d'O. rufipogon serait l'ancêtre direct d'O. sativa alors qu'O. breviligulata serait celui d'O. glaberrirna (Second, 1984). Deux espèces de riz sont principalement cultivées en Afrique : Oryza sativa L. (riz asiatique) et Oryza glaberrima Steud. (riz africain) (Anonyme, 1991, 2002) qui se distinguent par des caractéristiques spécifiques présentées dans le tableau 2 et illustrées par les photos 2 et 3 . L'espèce Oryza sativa fut introduite en Afrique de l'Ouest par les portugais vers les années 1500 (Pernes et al., 1984). 


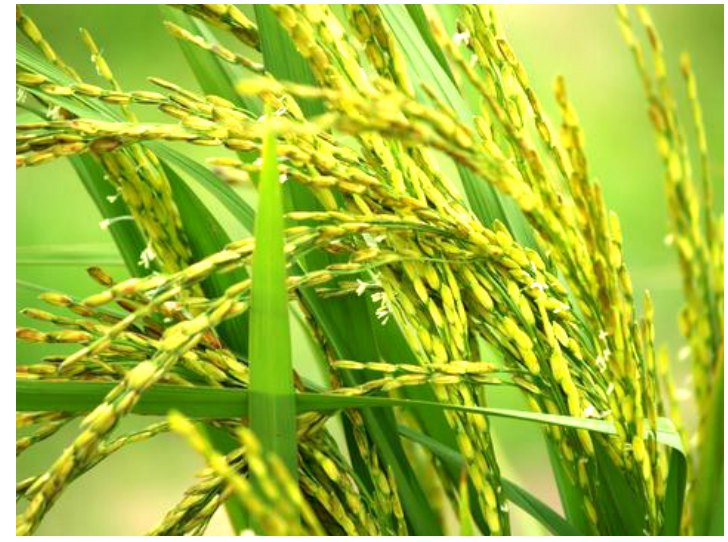

Photo 2 : Panicules d'Oryza sativa

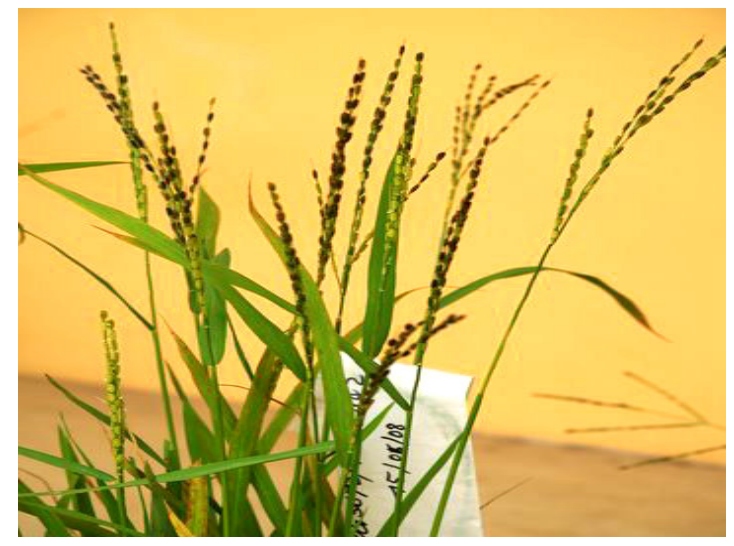

Photo 3 : Panicules d'Orvza glaberrima

\section{Source : www.AfricaRice.org}

Chez 0. sativa, on reconnaît trois grands types morphologiques. Le type indica se caractérise par un tallage fort, des feuilles étroites, des racines fines et un grain effilé. Les variétés de ce type sont celles de culture aquatique dans les régions tropicales de basse altitude (inférieure à 1200 mètres). Le type japonica qui se distingue par un tallage moyen, des feuilles étroites, des racines fines et un grain arrondi. Ce type est celui des variétés de culture aquatique en régions tempérées et en régions tropicales d'altitude élevée. Et le type javanica se définit par un tallage faible, des feuilles larges, des racines épaisses et profondes et un grain long et large. II s'agit des variétés de culture pluviale en régions tropicales et des variétés de culture aquatique aux EtatsUnis (Jacquot et al., 1992).

Tableau 2 : Quelques caractéristiques de différenciation de 0 . sativa et de 0. glaberrima.

Caractéristiques de différenciation

\begin{tabular}{l|l}
\hline Oryza sativa $L$. & Oryza glaberrima Steud. \\
\hline Plante annuelle & Plante annuelle \\
\hline Chaume souple, tallant bien & Chaume rigide \\
\hline Ligule longue, bifide, allongée & Ligule courte, tronquée, ovale \\
\hline Panicule penchée & Panicule dressée \\
\hline Pédicelles des épillets longs & Pédicelles des épillets courts \\
\hline Glumes presque toujours courtes & Glumes longues ou courtes \\
\hline Glumelles toujours hispides & Glumelles glabres ou hispides, souvent aristées \\
\hline Caryopse généralement blanc & $\begin{array}{l}\text { Caryopse souvent coloré en rouge rougeâtre, parfois grisâtre, plus } \\
\text { rarement blanc }\end{array}$ \\
\hline Cassure cornée ou semi cornée & Cassure généralement semi farineuse, plus ou moins cornée \\
\hline Trois groupes culturaux : hâtifs, semi hâtif, tardiff & Deux groupes culturaux : hâtif, très hâtif \\
\hline Épillets non caducs à maturité & Grand pourcentage d'épillets caducs à maturité \\
\hline Peu de dormance & Dormance des semences très prononcée \\
\hline
\end{tabular}
Source : (Boeken, 1971)

Le riz africain présente des caractères botaniques spécifiques qui permettent de le distinguer. Depuis l'époque précoloniale, le géographe Carney (2001) fait remarquer que l'illustration du plant de riz présente des caractéristiques qui sont typiques à l'espèce africaine: d'abord, le plant du riz présente une panicule dressée, c'est-à-dire qu'il y a une quasi-absence de ramifications secondaires (moins de branches, donc moins de graines). Ensuite, les glumelles sont aristées, c'est-à-dire qu'il y a un prolongement de l'apex correspondant à la présence de barbes (Vido, 2011). Chez le riz africain (Oryza glaberrima), deux agro-écotypes principaux sont observés chez cette espèce: un type dressé précoce et insensible à la photopériode qui est cultivé en pluvial ou 
en zone de bas-fonds modérément inondés, un type flottant tardif et photosensible cultivé dans les plaines inondables (Agnoun et al., 2012). Sa taille peut varier de 0,5 à $1 \mathrm{~m}$ en conditions de culture pluviale ou irriguée mais très supérieure ( $5 \mathrm{~m}$ et plus) en conditions de culture flottante.

\section{Conditions requises pour la production du riz} Principales écologies rizicoles et contraintes spécifiques: Le riz est cultivé dans des milieux très variés couvrant une large gamme d'altitudes et de latitudes. Cette plante, d'origine aquatique, et donc assez exigeante en eau par rapport à d'autres céréales, est surtout caractérisée par une grande plasticité vis-à-vis de ses conditions d'alimentation hydrique (Courtois, 1988). Sur la base de la topographie et de l'apport en eaux du riz (Windmeijer et al., 1994), 5 écologies ont été identifiées pour le riz: Riz de plateau pluvial dans les plateaux et pentes ;

- $\quad$ Riz de bas-fonds pluvial dans les vallées et plaines inondées ;
Riz irrigué avec contrôle de l'eau dans les deltas et plaines inondées ;

- $\quad$ Riz d'immersion profonde ou riz flottant, le long des berges et des lits de rivières ;

- $\quad$ Riz de mangrove dans les lagunes et deltas des zones côtières.

La Figure 3 présente un plan du continium plateau - basfonds qui résume en trois grands niveaux les écologies. Les principales contraintes inhérentes à la pratique rizicole en riziculture de bas-fonds sont présentées dans le Tableau 3. Généralement le riz 0 . sativa, pousse sur les sols secs ou inondés et sa température moyenne pendant la phase de croissance varie de 20 à $38^{\circ} \mathrm{C}$. Des températures nocturnes inférieures à $15^{\circ} \mathrm{C}$ peuvent entraîner une stérilité de l'épillet (ADRAO, 1995). Des températures supérieures à $21^{\circ} \mathrm{C}$ lors de la floraison sont nécessaires à l'anthèse et à la pollinisation. En système pluvial, des précipitations d'au moins $750 \mathrm{~mm}$ sur une période de 3 à 4 mois sont nécessaires et contrairement à l'espèce africaine, 0 . sativa est vulnérable à la sécheresse (ADRAO, 1995).

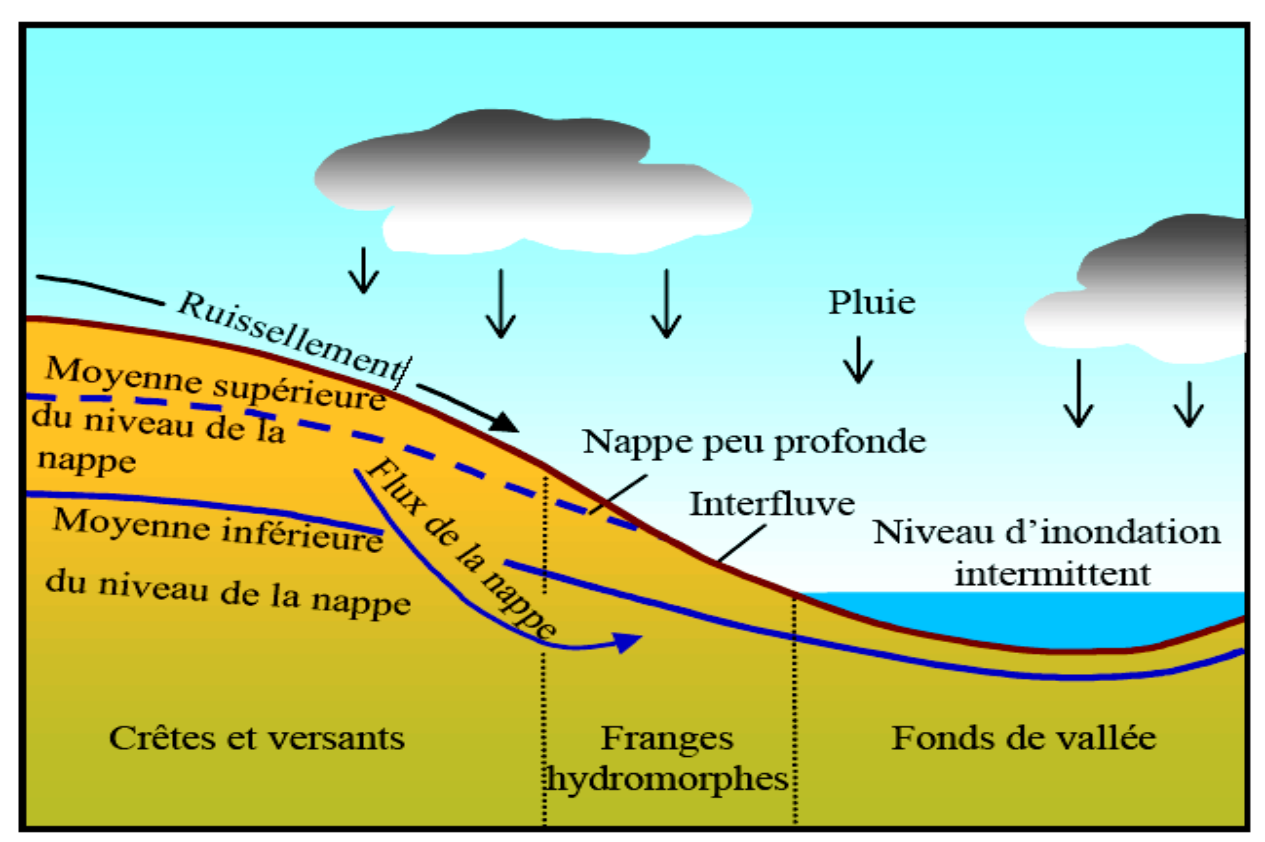

Figure 3 : Plan du continium plateau - bas-fonds.

Source : www.warda.org 
Gnacadja et al., J. Appl. Biosci. 2018 Revue analytique des performances agronomiques, nutritionnelles et perspectives de valorisation du riz africain (Oryza glaberrima)

Tableau 3: Différents stress inhérents rencontrés dans le continium plateau - bas-fonds

\begin{tabular}{l|l|l}
\hline Haut de pente & Bas de pente & Lit mineur \\
\hline $\begin{array}{l}\text { Sécheresse } \\
\text { Explosion des mauvaises }\end{array}$ & Mauvaises herbes & Mauvaise maitrise de l'eau \\
\hline Attaques d'insectes foreurs des tiges, & Gestion de l'eau & Déficience en N \\
\hline Attaque des termites,... & Sécheresse & Déficience en N \\
\hline Déficience en N et $\mathbf{P}$ & $\begin{array}{l}\text { Salinité, alcalinité / acidité } \\
\text { des eaux }\end{array}$ \\
\hline Érosion des sols, acidité des sols & ferreuse & $\begin{array}{l}\text { Brûlures bactériennes des } \\
\text { feuilles }\end{array}$ \\
\hline & Insectes & \\
\hline & foreurs de tiges & \\
\hline & Panachure jaune du riz & \\
\hline & Cécidomyie africaine & \\
\hline & Brûlures bactériennes des feuilles & \\
\hline
\end{tabular}

Source : www.warda.org

En Afrique de l'Ouest et du Centre, les systèmes - riz de plateau pluvial couvrent $44 \%$ tandis que les systèmes riz de bas-fonds pluviaux occupent $31 \%$ et enfin les systèmes - riz irrigué occupent $12 \%$ des surfaces rizicoles exploitées (WARDA, 2004). La culture du riz de mangrove et du riz flottant occupe des surfaces très minoritaires (Defoer, 2002). Les systèmes de production pluviaux demeurent prédominants et assurent plus de la moitié de la production totale (36\% pour les bas-fonds et $25 \%$ pour les plateaux). La plupart des écologies de production de riz présentent des ressemblances telles que la pression parasitaire, la baisse de la fertilité du sol et la pression accrue des mauvaises herbes (Rodenburg et Johnson, 2009). Cette dernière constitue le principal facteur limitant des systèmes de production rizicole en Afrique Subsaharienne.
Types de riziculture : La plupart des classifications des types de rizicultures se fondent sur sa grande plasticité (Courtois, 1988) à savoir :

Riziculture irriguée, endiguée (Photo 4) avec parfaite maîtrise de l'eau (apport comme retrait). - $\quad$ Riziculture inondée, endiguée, (Photo 5) sans maîtrise de l'eau qui peut être subdivisée en plusieurs catégories en fonction des risques plus ou moins élevés de sécheresse et/ou de submersion et de la hauteur d'eau dans la parcelle.

- $\quad$ Riziculture pluviale (Photo 6) dont l'alimentation hydrique dépend uniquement de la pluviométrie (riziculture pluviale stricte) ou de la présence d'une nappe éventuelle (riziculture de nappe).

- $\quad$ Riziculture flottante (Photo 7), qui suit la crue des grands fleuves.

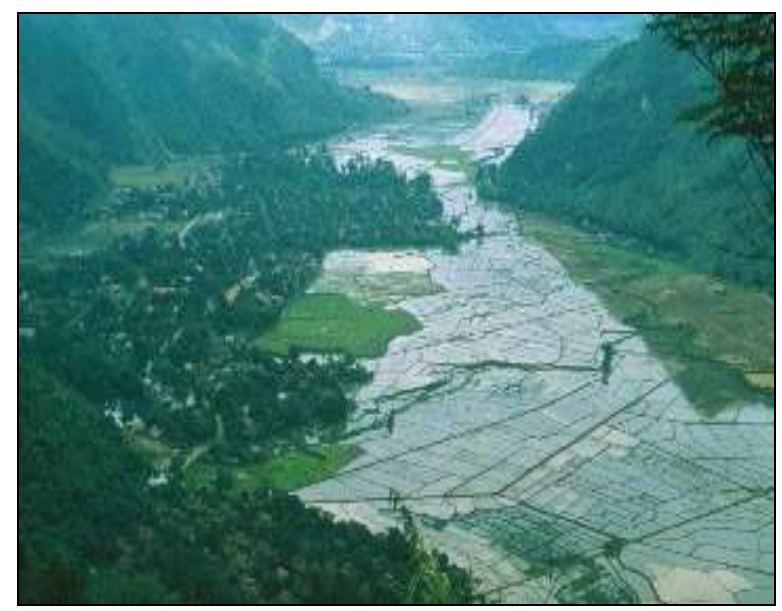

Photo 4 : Riziculture irriguée

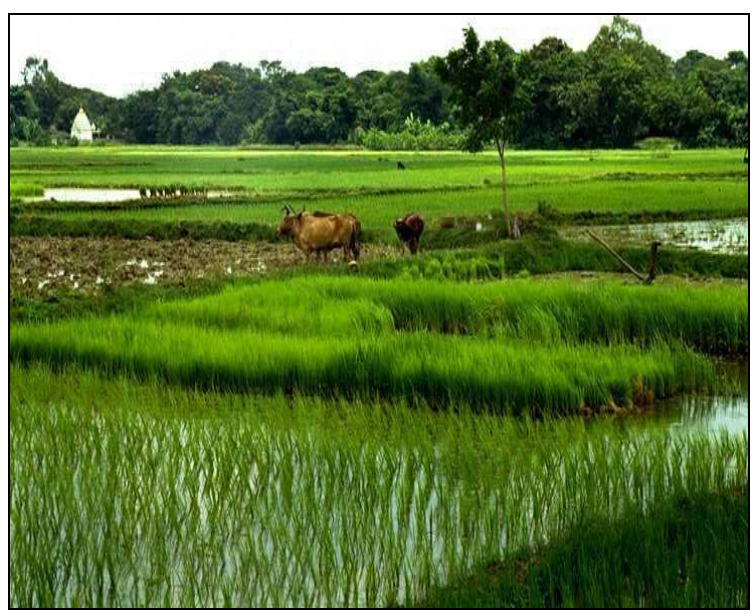

Photo 5 : Riziculture inondée 


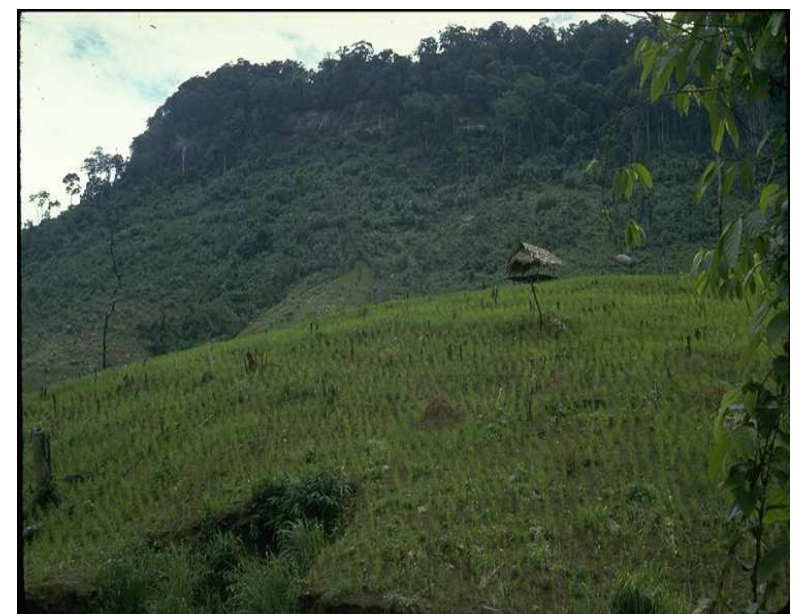

Photo 6 : Riziculture pluviale

Sources : (Courtois, 1988)

Principales zones de production: Les grands pays producteurs de riz sont les pays asiatiques notamment le Bangladesh, I'Inde, le Pakistan, la Thaïlande, le Vietnam, la Chine continentale et l'Indonésie. Ils sont également les principaux consommateurs (FAO, 2017). Les principales régions d'intense activité rizicole en Afrique sont ses zones Ouest et Est qui assurent près de $95 \%$ de la production rizicole (Sié et al., 2008). Selon les prévisions statistiques de la $\mathrm{FAO}$, en supposant des conditions de croissance normales, la production mondiale de riz paddy en 2017 pourrait atteindre 758,9 millions de tonnes (503,8 millions de tonnes, équivalent usiné). Ce chiffre représenterait une augmentation annuelle de 0,9 pour cent de la production et marquerait un probable ralentissement du taux de croissance de la production au cours de la prochaine campagne (Tableau 4) (FAO, 2017). En Afrique, des pluies irrégulières ont détérioré les perspectives de production à Madagascar et en République-Unie de Tanzanie, tandis qu'en Égypte, la production pourrait également baisser en raison d'une majeure utilisation des terres pour la culture du coton. Toutefois, en l'absence de revers majeur, les efforts continus visant à réduire la dépendance à l'égard des

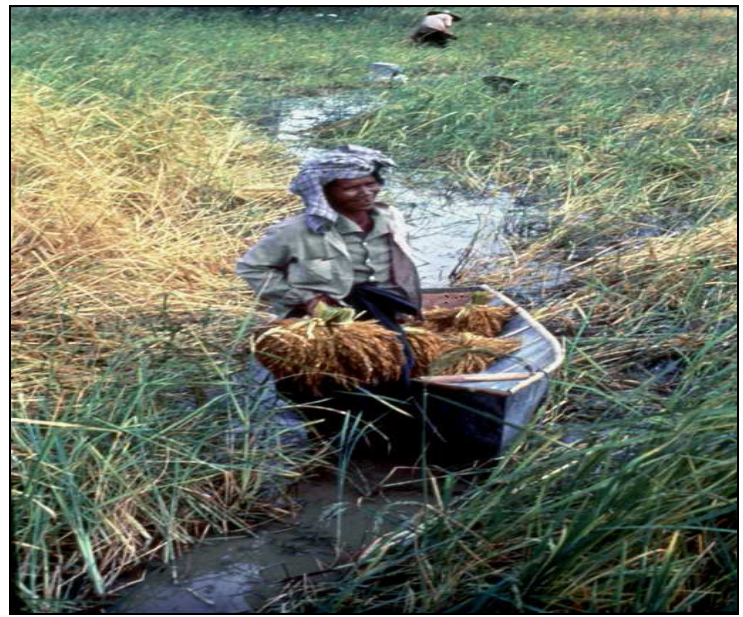

Photo 7 : Riziculture flottante

importations pourraient aboutir à de nouvelles progressions en Afrique de l'Ouest, et maintenir ainsi la production sur l'ensemble du continent à un niveau proche de l'excellente récolte de 2016 (FAO, 2017).

Analyse de l'importation du riz et corolaires pour les pays africains: Les efforts de production avec les prévisions de 2017 sont toujours en dessous des attentes pour l'autosuffisance alimentaire et l'Afrique se retrouve comme l'un des grands continents importateurs (Tableau 5). Le niveau de production qui répond difficilement à la demande fait que l'Afrique n'est pratiquement pas un continent exportateur de riz en dehors de l'Égypte qui fait un effort (Tableau 6). Après deux années consécutives de contraction, les expéditions mondiales de riz devraient se redresser partiellement au cours de l'année civile 2017 et s'établir à 43,3 millions de tonnes (équivalent usiné). Le redressement de 4 pour cent prévu en 2017 repose sur la perspective d'une accélération du rythme des achats de certains acheteurs clés en Asie et en Afrique - à savoir Madagascar, le Nigéria, les Philippines et le Sri Lanka en raison de déficits de production dans ces pays et des efforts visant à reconstituer leurs réserves (FAO, 2017). 
Gnacadja et al., J. Appl. Biosci. 2018 Revue analytique des performances agronomiques, nutritionnelles et perspectives de valorisation du riz africain (Oryza glaberrima)

Tableau 4: Production mondiale de riz paddy

\begin{tabular}{|c|c|c|c|c|c|c|c|c|}
\hline & 2012-2014 & 2015 & 2016 & 2017 & \multirow{2}{*}{\multicolumn{2}{|c|}{$\begin{array}{l}\begin{array}{l}\text { Variation } \\
\text { annuelle }\end{array} \\
2017 / 2016\end{array}$}} & \multicolumn{2}{|l|}{2017} \\
\hline & Moyenne & & Estimation & Prévision & & & Précédent & Révision \\
\hline & \multicolumn{4}{|c|}{ millions de tonnes } & & $\%$ & \multicolumn{2}{|c|}{ millions de tonnes } \\
\hline Monde & 741,5 & 740,3 & 751,9 & 758,9 & 7,0 & 0,9 & 748,0 & 3,9 \\
\hline Asie & 672,4 & 669,6 & 680,1 & 686,4 & 6,3 & 0,9 & 676,5 & 3,6 \\
\hline Afrique & 27,7 & 28,8 & 30,8 & 30,7 & $-0,1$ & $-0,4$ & 30,2 & 0,5 \\
\hline Afrique du nord & 6,1 & 5,9 & 6,3 & 6,2 & $-0,1$ & $-2,3$ & 6,3 & - \\
\hline Afrique de l'ouest & 13,5 & 14,3 & 15,4 & 16,0 & 0,6 & 3,6 & 15,3 & 0,1 \\
\hline Afrique centrale & 0,5 & 0,5 & 0,5 & 0,5 & 0,0 & 1,3 & 0,5 & - \\
\hline Afrique de l'est & 2,8 & 3,6 & 4,0 & 3,7 & $-0,3$ & $-7,5$ & 3,6 & 0,4 \\
\hline Afrique du sud & 4,6 & 4,3 & 4,3 & 4,1 & $-0,2$ & $-5,4$ & 4,3 & - \\
\hline Amérique centrale & 2,8 & 2,6 & 2,8 & 2,9 & 0,1 & 3,7 & 2,8 & 0,0 \\
\hline Amérique du sud & 24,2 & 25,7 & 23,7 & 24,9 & 1,2 & 5,1 & 23,3 & 0,4 \\
\hline Amérique du nord & 9,3 & 8,8 & 10,2 & 9,1 & $-1,0$ & $-10,3$ & 10,6 & $-0,5$ \\
\hline Europe & 4,1 & 4,2 & 4,2 & 4,1 & $-0,1$ & $-1,6$ & 4,3 & $-0,1$ \\
\hline Océanie & 1,0 & 0,7 & 0,3 & 0,9 & 0,6 & 229,3 & 0,3 & - \\
\hline
\end{tabular}

Source : (FAO, 2017)

Tableau 5: Importations mondiales de riz

\begin{tabular}{|c|c|c|c|c|c|c|c|c|}
\hline & $\begin{array}{l}2012- \\
2014\end{array}$ & 2015 & 2016 & 2017 & \multirow{2}{*}{\multicolumn{2}{|c|}{$\begin{array}{l}\begin{array}{l}\text { Variation } \\
\text { annuelle }\end{array} \\
2017 \text { / } 2016\end{array}$}} & \multicolumn{2}{|l|}{2017} \\
\hline & Moyenne & & Estimation & Prévision & & & Précédent & Révision \\
\hline & \multicolumn{4}{|c|}{ millions de tonnes } & & $\%$ & \multicolumn{2}{|c|}{ millions de tonnes } \\
\hline Monde & 42,1 & 44,9 & 41,6 & 43,3 & 1,7 & 4,0 & 42,9 & 0,4 \\
\hline Asie & 20,1 & 23,3 & 19,2 & 20,8 & 1,7 & 8,7 & 20,4 & 0,4 \\
\hline Afrique & 14,7 & 13,8 & 14,1 & 14,4 & 0,3 & 2,0 & 14,3 & 0,1 \\
\hline Amérique centrale & 2,0 & 2,2 & 2,4 & 2,3 & $-0,1$ & $-3,7$ & 2,3 & 00 \\
\hline Amérique du sud & 1,6 & 1,6 & 1,8 & 1,7 & $-0,1$ & $-6,2$ & 1,7 & 00 \\
\hline Amérique du nord & 1,1 & 1,1 & 1,2 & 1,2 & $-0,1$ & $-6,2$ & 1,2 & 0,0 \\
\hline Europe & 2,0 & 2,3 & 2,3 & 2,3 & 0,0 & $-0,4$ & 2,4 & $-0,1$ \\
\hline Océanie & 0,5 & 0,5 & 0,5 & 0,5 & 0,0 & 1,7 & 0,5 & 0,0 \\
\hline
\end{tabular}

Source : (FAO, 2017).

Tableau 6: Exportations mondiales de riz

\begin{tabular}{l|l|l|l|l|l|l|l|l}
\hline & $2012-2014$ & 2015 & 2016 & 2017 & \multicolumn{2}{l|}{$\begin{array}{l}\text { Variation } \\
\text { annuelle }\end{array}$} & \multicolumn{2}{l}{2017} \\
\hline & Moyenne & \multicolumn{2}{l|}{ Estimation } & Prévision & $2017 / 2016$ & \multicolumn{2}{l}{ Précédent } & Révision \\
\hline & millions de tonnes \\
\hline Monde & 42,1 & 44,9 & 41,6 & 43,3 & 1,7 & 4,0 & 42,9 & 0,4 \\
\hline Asie & 34,0 & 37,2 & 33,5 & 35,3 & 1,8 & 5,3 & 34,9 & 0,4 \\
\hline Afrique (Égypte) & 0,6 & 0,5 & 0,6 & 0,5 & $-0,1$ & $-23,3$ & 0,6 & $-0,1$ \\
\hline Amérique du sud & 3,3 & 2,9 & 3,3 & 3,2 & 0,0 & $-1,2$ & 3,1 & 0,1 \\
\hline Amérique du nord & 3,2 & 3,4 & 3,5 & 3,6 & 0,0 & 0,3 & 3,6 & - \\
\hline Europe & 0,4 & 0,4 & 0,5 & 0,4 & 0,0 & $-8,5$ & 0,4 & 0,0 \\
\hline Océanie & 0,5 & 0,3 & 0,2 & 0,3 & 0,1 & 79,9 & 0,4 & $-0,1$ \\
\hline
\end{tabular}

Source : (FAO, 2017) 

perspectives de valorisation du riz africain (Oryza glaberrima)

Le centre de riz pour l'Afrique (AfricaRice) a estimé qu'au regard des tendances depuis 2008 la production et la consommation du riz connaitraient une croissance exponentielle d'ici 2020 (Africarice, 2011). Les besoins de riz de l'Afrique de l'Ouest sont assurés à plus de $40 \%$ par le marché international. Les importations de riz ont fortement augmenté au cours des deux dernières décennies, de 6,5\% par an passant de moins de 2 millions de tonnes à près de 8 millions. Aujourd'hui, elles représentent $70 \%$ des importations céréalières d'Afrique subsaharienne et $20 \%$ des importations mondiales de riz. Cette tendance est générale dans tous les pays de la région, même si le poids de certains d'entre eux - Nigeria, Sénégal, Cote d'ivoire - est déterminant (Mendez del villar et Bauer, 2013). La réduction de la dépendance vis-à-vis des importations de riz est susceptible d'être un projet coûteux et à long terme, même à la lumière des investissements prévus et en cours dans le secteur du riz. En effet, les importations de riz de certains pays pourraient continuer à augmenter. Ceci est particulièrement vrai dans les pays non couverts par l'examen de l'USDA, tels que le Nigeria, compte tenu de la croissance rapide de la demande des consommateurs (USDA, 2013).

Production du riz africain : un défi pour la réduction de l'importation: Le riz africain 0 . glaberrima est essentiellement cultivé en Afrique de l'Ouest. Bien qu'en constante déclin, sa production est localisée au nord dans le Sud-Ouest de la Mauritanie et le centre du Mali, et au sud sur toute la côte du Golfe de Guinée. La zone de production du riz africain s'étend par ailleurs de la côte sénégalaise jusqu'au Sud-Ouest du Tchad (Nayar, 2012).Les systèmes de riziculture ouest africains sont d'une grande diversité. Le riz de mangrove et de basfonds prédominent dans les zones côtières le long du golfe de Guinée, tandis que le riz pluvial est cultivé dans des zones de plateaux comme en Guinée, dans le Sud du Mali, dans I'Ouest du Benin et au Nigeria. Le riz irrigué occupe trois grandes zones : la vallée du fleuve Sénégal, I'office du Niger au Mali, et l'état de Kano au Nigeria. Des périmètres rizicoles de petite taille se développent le long des cours d'eau permanents mais aussi temporaires avec l'aménagement des bas-fonds en zone de savane (Mendez del villar et al., 2011).

Performances agronomiques du riz africain : Plusieurs travaux ont décrit les exigences ou conditions de culture du riz local. En effet, le riz africain pousse bien au-dessus de $30^{\circ} \mathrm{C}$, mais au-dessus de $35^{\circ} \mathrm{C}$, la fertilité des épillets diminue considérablement. Les températures inférieures à $25^{\circ} \mathrm{C}$ réduisent la croissance et le rendement (Sié et al., 2009). O. glaberrima est généralement une plante de jours courts, mais sa photosensibilité varie selon les écotypes, depuis les plantes non sensibles jusqu'aux plantes très sensibles (Bezançon et Diallo, 2006). En ce qui concerne le sol, le riz africain est cultivé sur une large gamme. La disponibilité en eau est une condition adéquate pour toute riziculture mais l'espèce africaine a des prédispositions naturelles à résister à la sécheresse (Sié et al., 2009). Le riz africain est essentiellement cultivé en deux écologies (pluvial de plateau et bas-fond inondé). Selon Montcho et al., (2010), il est classé en deux groupes écologiques : type plateau et type flottant. Sur cette base, Bezançon (1993) et Ndjiondjop (1996), distinguent deux agro écotypes principaux :

un type dressé précoce et insensible à la photopériode qui est cultivé en pluvial ou en zone de basfonds modérément inondé;

$>\quad$ un type flottant tardif et photosensible cultivé dans les plaines inondables (Bezançon, 1993; Ndjiondjop, 1996).

Montcho et al (2017) précisent également que certaines accessions de 0 . glaberrima classées comme type plateau sont adaptées aux conditions de bas-fond et d'eau profonde, et vice-versa. De nos jours, le riz africain est rarement cultivé en culture pure. II est souvent associé au riz asiatique qui est de plus en plus dominante sur le continent (Nayar, 2012).

Potentialités génétiques du riz africain: Oryza glaberrima est une espèce qui renferme des ressources génétiques encore inexploitées (Pham, 1992) qui pourraient être utilisées, pour l'instant, à l'intensification de certains types de riziculture, tels que la riziculture de bas-fonds. C'est une espèce qui possède de nombreuses qualités (Bezançon et Diallo, 2006): résistance à la sécheresse, rusticité et capacité de l'espèce à lutter contre les mauvaises herbes, résistance à la pyriculariose, à la panachure jaune du riz, aux insectes et nématodes et une bonne vigueur des plants. Les infestations d'adventices sont l'une des principales causes des faibles rendements dans les écosystèmes pluviaux et hydromorphes. Pour résoudre ce problème, le Docteur Monty Jones et ses collaborateurs ont évalué plusieurs variétés d'O. glaberrima et de 0 . sativa avec des niveaux d'intrants différents. Les résultats ont permis de montrer que seules les variétés du riz africain (IB19, IG10, CG14, CG20 et Biyagero) se sont caractérisées par le nombre élevé de talles et une surface foliaire importante (Jones et Dingkuhn, 1997). O. glaberrima peut survivre dans des conditions de faibles apports en intrants et de compétitivité avec les herbes indésirables (Sarla et Swamy, 2005) de même que dans des écosystèmes difficiles telles que les zones très 
pluvieuses, les zones côtières, les zones de mangrove et même les zones accidentées (Bezançon et Diallo, 2006). Sa capacité de compétitivité face aux adventices est due à une bonne vigueur, une croissance végétative très rapide, un faible coefficient d'extinction et une utilisation efficace de la lumière (Bezançon et Diallo, 2006). Elle possède des feuilles pendantes qui évitent que les rayons solaires n'atteignent le sol. En plus de sa grande accumulation de biomasse aérienne, elle possède de nombreuses racines minces avec une bonne exploration de la rhizosphère, l'aidant à lutter effectivement et efficacement contre les adventices. Aussi, l'espèce a-telle un tallage abondant et une bonne canopée lui permettant d'étouffer et d'éliminer les adventices (ADRAO, 2002). En plus de sa capacité à lutter contre les adventices, l'espèce 0 . glaberrima dispose d'autres caractéristiques avantageuses qu'a énumérées ADRAO en 2002. II s'agit de:

- la maturité précoce : 0 . glaberrima arrive, en général, à maturité entre 90 et 100 jours par rapport aux variétés 0 . sativa améliorées pluviales qui n'arrivent à maturité qu'entre 120 et 140 jours en Afrique de l'Ouest ;

- la tolérance à la sécheresse ;

- la résistance à la cécidomyie africaine du riz ;

- la résistance au virus de la panachure jaune, une maladie importante en riziculture irriguée et de bas-fond ; - la résistance à la pyriculariose ;

- le goût, l'arôme et d'autres qualités de grains prisées par les paysans.

Beaucoup de travaux de recherche menés par AfricaRice sur les accessions de riz africain, attestent que des mécanismes adaptatifs ont permis aux espèces de riz indigènes de survivre malgré les stress abiotiques et biotiques prévalant dans les différentes écologies rizicoles en Afrique. La rusticité de 0 . glaberrima lui a permis de résister à l'extinction face à la diffusion des variétés asiatiques (ADRAO, 2004). A ce jour, plus de 2500 accessions de 0 . glaberrima sont collectées à travers les pays africains producteurs et conservées dans la banque de semences de AfricaRice.

Résistance aux insectes et à la sécheresse : Certains cultivars appartenant l'espèce 0 . glaberrima représentent une source de résistance aux insectes rencontrés dans la sous-région. Nwilene et Williams (2002), ont montré que des variétés de l'espèce africaine de riz présentent une bonne résistance à la cécidomyie africaine des galles. Au nombre des stress abiotiques, la sécheresse est la contrainte majeure qui affecte les rendements du riz. Cependant, certaines variétés d'Oryza glaberrima sont tolérantes à la sécheresse. Leur capacité à mûrir tôt et à synchroniser la maturité vers la fin de la saison pluvieuse est mise en évidence. Leurs feuilles minces s'enroulent rapidement pour retenir l'eau et les racines fines pénètrent efficacement le sol et rentrent en contact avec les particules du sol pour prélever l'eau et les nutriments nécessaires (Dingkuhn et al., 1999 ; Maji et al., 2001).

Résistance aux maladies et à la verse : La panachure jaune du riz est aujourd'hui présente dans la région ouest africaine, précisément dans les bas-fonds et les périmètres irrigués. La plupart des cultivars de riz de basfonds populaires sont sensibles à cette affection virale. Pour répondre à ce défi, plusieurs travaux de recherche ont été effectués. Attere et Fatokun(1983) ont identifié 13 accessions d'O. glaberrima comme résistantes au virus. A partir du test ELISA, Thottapilly et Rossel (1993), ont déterminé 05 cultivars immuns, TOG 5379, TOG 5674, TOG 5681, TOG 7235 et TOG 7291. D'autres travaux ont permis de confirmer que TOG 5681 ne présentait aucun symptôme de panachure jaune, même après inoculation d'isolat, 10 à 20 jours après la germination (Ndjiondjop et al., 1999). L'un des points faibles des variétés appartenant à l'espèce 0 . glaberrima est sa sensibilité à la verse. Néanmoins, certaines d'entre elles, notamment Old Ayoma, Fufore-Yole, CG66, Katasinaala et Shendam présentent une bonne résistance à la verse (Jones et Dingkuhn, 1997).

Résistance à la toxicité : Le riz pluvial est souvent cultivé sur des sols ferralitiques acides à teneur extrêmement faible en phosphore et fréquemment sujets à la toxicité en aluminium et en magnésium. Des recherches récentes ont permis de montrer que la variété WAC 102531 présente une bonne tolérance à la toxicité en aluminium (Baggie et al., 2002). Quant à la toxicité ferreuse, elle constitue une contrainte majeure pour la riziculture irriguée. Elle peut provoquer, en fonction de l'intensité du stress, 12 à 100\% de réduction du rendement (Sahrawat et al., 1996). Les travaux effectués par AfricaRice pour identifier les génotypes tolérants ont montré que CG14 ne présente aucun symptôme de toxicité ferreuse. II est par conséquent un génotype important dans le cadre des programmes de croisement en vue d'obtenir des descendances tolérantes (Sahrawat, 2004). Toutes ces potentialités révélées pour certaines variétés de riz africain (O.glaberrima) ou des variétés améliorées issus des parents 0. glaberrima témoignent de l'importance et de la valeur qu'il est encore nécessaire d'accorder à l'espèce afin de poursuivre à partir de ces connaissances la recherche élargie à toutes les variétés non identifiées au niveau des niches de conservation du riz africain.

Caractéristiques nutritionnelles du riz africain : Très peu de travaux se sont intéressés spécifiquement aux 

perspectives de valorisation du riz africain (Oryza glaberrima)

valeurs nutritionnelles du riz africain contrairement aux aspects génétiques pour le développement des variétés plus résistantes. Toutefois les études ont montré que généralement le riz est un aliment énergétique de bonne valeur nutritionnelle avec une prédominance glucidique. L'amidon de riz, constituant glucidique majeur, se caractérise par une digestibilité élevée, raison pour laquelle le riz est utilisé, généralement sous forme de farine, dans les aliments infantiles (Laureys et Geeroms, 2002). Le riz africain est apprécié par les consommateurs des zones productrices qui sont essentiellement les producteurs eux-mêmes. Selon Sié (2007), le riz asiatique se digère très vite alors que le riz africain est moins digeste. Cette observation pourrait s'expliquer par une éventuelle différence de la composition en nutriments de ces deux espèces qui demeurent à ce jour celles consommées. Toutefois, sans donner de détail sur les espèces, Romain (2001), indique que le riz décortiqué (sur lequel l'enveloppe de glume est enlevée) contient environ $12 \%$ d'eau, $76 \%$ de glucides, $1 \%$ de lipides, $10 \%$ de protides et $1 \%$ de matières minérales. II est plus riche en glucides que le riz paddy (non décortiqué). Les différences à l'intérieur d'une même variété de riz sont souvent méconnues, bien que des recherches, effectuées principalement à l'Institut International de Recherche sur le riz (IRRI), aient montré que la composition varie sensiblement d'une variété à une autre (Chandrasekhar et Mulk, 1970; Juliano et Villareal, 1993). L'IRRI a étudié la teneur protéique de plus de deux mille variétés de riz et a trouvé des teneurs variant de 4 à 14 pour cent pour les variétés d'Oryza sativa et de 9 à 14 pour cent pour les variétés d'Oryza glaberrima. D'autres études effectuées ont montré que les variétés de l'espèce Oryza glaberrima ont un taux de protéine plus élevé (en moyenne 11.56\%) que celles de l'espèce Oryza sativa (en moyenne 7,86\%) (Watanabe et al., 2004). Elles sont également riches en éléments nutritifs et constituent pour la plupart une bonne source de glucides complexes. Elles contiennent très peu de matières grasses, de sel et de cholestérol. Plusieurs variétés locales sont une bonne source de vitamines (thiamine, niacine, riboflavine, vitamine D), de minéraux (fer et calcium) et de fibres (Frei et Becker, 2004 ; Montecinos et al., 2011). Certains résultats de recherche suggèrent que le riz noir à forte teneur en anthocyanine peut prévenir les risques de cancer (Chang, 2010). La richesse que représente la variabilité des caractères quantitatifs complexes demeure inexploitée ou sousexploitée. Pour contribuer de façon plus large aux objectifs de caractérisation, Joseph et ses collaborateurs ont récemment classé 1.020 accessions de 0 . glaberrima d'Afrique de l'Ouest sur la base des données relevant de leurs caractéristiques d'empesage et de leur teneur apparente en amylose. Cette étude a montré qu'il existe un niveau élevé de diversité génétique dans les accessions de 0 . glaberrima de la sous-région ouest africaine. Cette diversité suggère qu'il peut y avoir une ressource précieuse d'un pool de gènes potentiellement important (au plan nutritionnel) qui peut être bénéfique pour la sélection variétale (Gayin, 2015).

Contraintes liées à la valorisation du riz africain : La question de valorisation du riz africain constitue un défi de compétitivité face aux autres espèces de riz. La compétitivité du riz africain a été le sujet d'un long débat depuis les années 1980. L'absence d'un avantage comparatif dans la production du riz avait été utilisée comme argument pour tolérer la dépendance de l'Afrique aux importations du riz (Pearson et al., 1981). Plusieurs années après la mise en place des premières mesures de libéralisation des filières rizicoles, le maintien de la part des importations dans l'approvisionnement des consommateurs africains témoigne des limites des stratégies de libéralisation comme cadre de relance de la riziculture ouest-africaine (Lançon et Mendez del villar, 2012). Certes, la mise en place de ces réformes a coïncidé avec une baisse des cours mondiaux du riz (Dawe, 2012), qui a rapidement annihilé les gains de compétitivité escomptés suite à la dévaluation du franc CFA. Cependant, des études récentes ont révélé une baisse des CRI (Coûts en Ressources Intérieures) dans différents pays, indiquant que la compétitivité-prix du secteur riz en Afrique a été améliorée depuis la crise alimentaire en 2008 (Seck, 2010). La faible productivité et les coûts importants de transformation et de commercialisation entravent la compétitivité des productions de riz local sur le marché international (Mendez del villar et al., 2011).

Amélioration des performances agronomiques et nutritionnelles: L'espèce africaine de riz cultivé $O$. glaberrima est reconnue comme une ressource génétique intéressante pour augmenter la diversité génétique du riz asiatique 0 . sativa et élargir l'adaptation des variétés dans les écosystèmes de riz en Afrique (Kiepe et al., 2010). Les travaux de création des variétés interspécifiques $(0$. sativa $x \quad 0$. glaberrima) ont été entamés par le Centre du Riz pour l'Afrique (AfricaRice) sur la base de la combinaison de la résistance du riz africain aux contraintes locales (en Afrique de l'Ouest et du Centre), avec le fort potentiel de rendement du riz asiatique (Futakuchi et Sié, 2009). Ces travaux ont abouti à la création d'une génération de variétés performantes de riz dénommée NERICA (New Rice of Africa). Le NERICA a également hérité la résistance à la sécheresse 

perspectives de valorisation du riz africain (Oryza glaberrima)

et aux nuisibles. II pousse mieux sur les sols acides et infertiles (Volvey et al., 2005). Au total, 18 variétés NERICA pluviales, développées par Monty Jones, et 60 variétés NERICA de bas-fond, développées par Moussa Sié et les partenaires, ont été mises au point par AfricaRice. Ces variétés ont été le premier succès à grande échelle du croisement des deux espèces cultivées de riz (Africarice, 2010). L'introduction et l'adoption rapide des variétés NERICA dans le Sahel, grâce aux sélections variétales participatives (PVS en anglais), ont entraîné une augmentation de la production rizicole se traduisant par un impact positif sur le bien être des producteurs et la réduction de la pauvreté (Obilana et Okumu, 2005). Toutefois, le succès des variétés NERICA ne satisfait pas totalement les ambitions des sélectionneurs et les espérances des producteurs. II existe toujours un écart défavorable entre les NERICA et leur parent 0 . glaberrima du point de vue résistance/tolérance aux contraintes biotiques et abiotiques (Futakuchi et Sié, 2009; Africarice, 2010). Ce constat interpelle les sélectionneurs à améliorer les aptitudes des variétés NERICA afin qu'elles soient plus productives et mieux adaptées. Des activités de recherche dans ce sens ont été menées et des résultats intéressants obtenus ont montré que les croisements 0 . glaberrima $x$ O sativa menés par AfricaRice ont permis la création des variétés TGS (Transgressive-segregant) qui présentent un nombre élevé de talles (Africarice, 2010). Par ailleurs, l'amélioration du riz africain par des croisements intra spécifiques ( 0 . glaberrima x 0 . glaberrima) est aussi envisagée dans les nouvelles orientations de l'amélioration variétale du riz en Afrique. Ces projections découlent des travaux de recherche de Futakuchi et Sié (2009), sur le potentiel de rendement du riz africain. Lesdits travaux révèlent qu'avant l'égrenage spontanée, le riz africain n'a pas moins d'épillets/panicule que le riz asiatique ; et que le rendement moyen du riz africain en condition de toxicité ferreuse et sans apport de fertilisant, est très proche de celui du riz asiatique tolérant à la toxicité ferreuse (2,8t/ha pour le riz africain et 2,9t/ha pour le riz asiatique). Ce rendement dépasse celui du riz asiatique sensible à la toxicité ferreuse (2,4t/ha) (Futakuchi et Sié, 2009 ; Africarice, 2010).

Analyse et Perspectives de recherche

Analyses des résultats de recherche : Le riz africain revêt aux yeux des peuples qui le cultivent une importance socioculturelle. Les recherches ethnographiques de Brydon (1981) permettent de montrer la place qu'occupe le riz africain dans l'agriculture des peuples de l'Afrique occidentale. Du point de vue cultural, Vido (2011) précise que c'est le cycle cultural de la céréale qui régit l'année agricole et la date d'autres rituels. La céréale africaine, cuite de diverses manières est également la nourriture rituelle la plus importante. Le riz africain est aussi utilisé parmi les repas donnés pour renforcer une nourrice à la naissance d'un enfant (Vido, 2011). Dans beaucoup de milieux Ouest-Africain où 0 . glaberrima est cultivé, cette denrée fait objet d'une fête traditionnelle juste après la moisson, qui conditionne le mangé des nouvelles récoltes entre temps interdit. Brydon (1981) précise que deux semaines après avoir fait les cérémonies qui précèdent la récolte du riz africain, le nouveau riz est offert à «ayapo», la principale divinité des «Avatime» pour implorer la bénédiction de la divinité et lever ainsi l'interdiction de consommer le riz avant les nouvelles récoltes. Aujourd'hui, dans la Préfecture de Kpélé et de Danyi (Région des plateaux) au Togo, une fête est célébrée chaque année pour le riz. Cette fête est désignée sous le nom de« Mozan », ce qui signifie littéralement dans le dialecte du milieu « la fête du riz ». Les nombreux résultats de recherche sur le riz africain montrent que pendant plus de 3500 ans 0 . glaberrima, l'espèce africaine de riz cultivé a contribué à la sécurité alimentaire de certaines populations et a résisté à l'extinction à la faveur des variétés de riz asiatique hautement productives introduites et largement cultivées au cours de ces 500 dernières années en Afrique SubSaharienne. Parfois, les petits paysans africains retournent à l'espèce de riz africaine cultivée lorsque leurs variétés modernes échouent à cause des stress biotiques ou abiotiques (Kiepe et al., 2010). En Afrique Sub Saharienne, la riziculture est pratiquée dans près de 38 pays (Balasubramanian et al., 2007). L'importance de cette étendue rizicole avec les différents systèmes de culture adaptés en Afrique devraient expliquer une dynamique de diffusion et l'évolution des différentes variétés avec des possibilités d'introgression des caractères d'adaptation créant éventuellement une diversité génétique au sein de l'espèce. Les variétés locales jouent un rôle important dans le développement de la résistance aux nuisibles et aux maladies fongiques (Taguchi-shiobara et al., 2013). Elles présentent de bonnes caractéristiques qualitatives (Lai, 1995). Le centre de riz pour l'Afrique (AfricaRice) a estimé qu'au regard des tendances depuis 2008 la production et la consommation du riz connaitraient une croissance exponentielle d'ici 2020 (Africarice, 2010). Les statistiques publiées par la FAO montrent que les besoins de riz de l'Afrique de l'Ouest sont assurés à plus de $40 \%$ par le marché international. Les importations de riz ont fortement augmenté au cours des deux dernières décennies, de 6,5\% par an passant de moins de 2 
millions de tonnes à près de 8 millions. Aujourd'hui, elles représentent $70 \%$ des importations céréalières d'Afrique subsaharienne et $20 \%$ des importations mondiales de riz. Cette tendance est générale dans tous les pays de la région, même si le poids de certains d'entre eux (Nigeria, Sénégal, Cote d'ivoire) est déterminant (Mendez del villar et Bauer, 2013). La réduction de la dépendance vis-à-vis des importations de riz est susceptible d'être un projet coûteux et à long terme, même à la lumière des investissements prévus et en cours dans le secteur du riz. En effet, les importations de riz de certains pays pourraient continuer à augmenter. Par ailleurs, les systèmes d'urbanisation, la croissance démographique et les différents régimes alimentaires sont les facteurs sociaux sensibles qui ont contribué à la forte consommation du riz en Afrique Sub Saharienne. La culture du riz avec perspective d'accroissement des productions constituent toujours un grand enjeu agricole pour plusieurs pays africains dans la dynamique permanente de l'autosuffisance alimentaire. Bien que les rendements productifs soient de nos jours fortement estimés avec les variétés améliorées, la problématique alimentaire que pose cet intérêt particulier à la riziculture suscite tout de même la question d'amélioration variétale dans laquelle le riz traditionnel africain retrouve toujours sa place: d'où l'importance de conservation et de valorisation de l'espèce. Le secteur du développement agricole en Afrique se rend compte qu'il est nécessaire de mener des recherches sur la demande et les préférences des consommateurs de riz afin d'améliorer la compétitivité des chaînes de valeur du riz (USAID, 2009). Il est évidence que le riz local africain peut être compétitif vis-à-vis du riz importé à condition que sa qualité soit adaptée aux exigences des consommateurs et des recherches sur l'identification et l'amélioration variétale puissent rendre performantes ses potentialités agronomiques au plan plus large. La nécessité d'étude ou d'exploration sur cette espèce s'avère important car non seulement, elle retrouve sa zone de culture occupée par les variétés asiatiques ou améliorées mais aussi ses potentiels agronomiques (résistance aux stress, aux maladies) sont prisés dans les processus d'amélioration variétale. II ressort au vue de ces valeurs qu'au-delà des potentialités agronomiques et génétiques, le riz africain a une importance socio-culturelle sur laquelle les populations se sont toujours basées pour lui accorder le choix de production et de consommation. Une voie de recherche explorant les caractéristiques non élucidées jusque-là du riz africain apportera beaucoup d'éléments de précision sur ces connaissances endogènes afin de mieux sensibiliser les populations sur ce patrimoine agricole pour lequel ils avaient déjà un intérêt de choix.

Perspectives de recherche : L'analyse des résultats de recherche sur le riz africain montre qu'il existe un vide sur la ligne de recherche scientifique visant l'utilisation complète des caractéristiques intéressantes du riz africain. Malheureusement O. glaberrima est actuellement menacées d'extinction. Une caractérisation agronomique associée à une étude basée sur les aspects qualité grain visant l'amélioration des propriétés culinaires et sensorielles garantiront l'utilisation de la diversité du riz africain pour aider dans le développement de futures variétés de riz commerciales acceptables qui ont de bons potentiels agronomiques répondant aux aspirations $d u$ producteur et de bonnes qualités sensorielles et organoleptiques souhaitées pour atteindre les préférences des consommateurs. II s'avère alors important, d'explorer les atouts des variétés de riz africain et d'étudier la performance des paramètres déterminant son rendement productif et ses qualités sensorielles pour la sécurité alimentaire des populations. De cette analyse, il ressort qu'il serait nécessaire d'entreprendre le développement de variétés performantes intra spécifiques de riz africain pour non seulement une amélioration variétale, mais aussi une croissance notable et durable de la production locale de nos pays. Cette situation appelle la nécessite d'identifier à travers un plan de recherche structurée, les variétés performantes qui pourraient encore cacher des potentiels intéressants pour le sélectionneur qui veut satisfaire autant les ambitions du producteurs que celles du consommateur en vue d'une valorisation qui est indispensable à la compétitivité et à la réduction des flux d'importation.

Quelques questions de recherche: L'arrivée de l'espèce asiatique de riz dans l'espace africain en général, et dans la sous-région ouest-africaine en particulier a contribué à faire reculer la culture du riz traditionnel Oryza glaberrima.

- $\quad$ Est-il possible d'améliorer le rendement et le potentiel organoleptique du riz africain ?

- Les techniques d'amélioration variétale peuventelles permettre d'obtenir des variétés intéressant autant le producteur que le consommateur?

- $\quad$ Quels sont les stratégies de valorisation du riz africain pour sa compétitivité ? 


\section{CONCLUSION}

Le riz africain (Oryza glaberrima), en dépit de son faible potentiel de rendement dû à la verse et à l'égrenage, est toujours cultivé localement pour sa rusticité, son goût et son arôme (Sié et al., 2008). II constitue un véritable réservoir de gènes de résistance ou de tolérance à de nombreux stress environnementaux et présente également une grande diversité variétale lui permettant de s'adapter à plusieurs types d'habitat (WARDA, 2005). Le riz africain constitue également un patrimoine génétique et socio-culturel important qui possède de bons potentiels et de valeurs socio-alimentaires appréciables. Actuellement menacé de disparition en faveur du riz asiatique, il est important de valoriser le riz africain, non seulement pour sa compétitivité, mais aussi pour une utilisation complète de ses potentiels déjà utilisés pour l'amélioration variétale. Au-delà d'un intérêt de protection et de préservation d'un patrimoine culturel, c'est également un chalenge pour faire face aux défis existant

\section{RÉFÉRENCES}

Aboa K, Dantsey-Barry H, Kpemoua KE, 2007. Le riz (Oryza spp.). in : Agbobli. C. A. ADOMEFA K. Situation de référence pour les principales céréales au Togo : Riz, maïs, mil, sorgho. Lomé ITRA, 39 - 68107.

ADRAO, 1995. Manuel du formateur. 395.

ADRAO, 2002. NERICA : le riz, source de vie. Bouaké, $8 p$.

ADRAO, 2004. Improving Rice Grain quality and competitiveness through BetterHarvest and Post-Harvest Technologies. Bamako Mali.

AFRICARICE, 2010. New Breeding Directions at AfricaRice: Beyond NERICA. Cotonou, Benin: $.24 \mathrm{pp}$.

AFRICARICE, 2011. Acquis de la crise rizicole : politiques pour la sécurité alimentaire en Afrique. Cotonou, Bénin: ii+26 pp.

Agnoun Y, Biaou SS, Sie M, Vodouhe RS, Ahanchede A, 2012. The African Rice Oryza glaberrima Steud: Knowledge, Distribution and prospects. International Journal of Biologie, (4) (3) 23

Anonyme, 1991. Mémento de l'agronome. Paris, Ministère de la coopération et du développement. 687 - 716 (1635).

Anonyme, 2002. Mémento de l'agronome, Ministère des affaires étrangères - CIRAD -GRET. 799 - 811 (1687).

ANSES, 2008. Valeurs nutritionnelles pour $100 \mathrm{~g}$ riz blanc cuit; Tableau de composition nutritionnelle. Ciqual. dans le système agricole, en particulier la filière rizicole en Afrique. Cette étude de synthèse apporte un bilan partiel des valeurs et potentiels identifiés pour le riz africain. Toutefois, elle relève également les idées ou raisons qui jusque-là sont en défaveur du riz africain. Alors que malgré quelques faiblesses qu'on lui attribue, le riz africain a pourtant été très résistant et a offert grâce à ses potentiels génétiques plusieurs perspectives de développement de variétés améliorées. De ce fait il est alors important, dans ce contexte d'amélioration des potentiels de semences et d'obtention de variétés plus résistantes et plus performantes afin de faire face aux défis agricoles, d'explorer davantage les potentiels et autres atouts du riz africain pour sa valorisation; car la valorisation du riz africain peut-être bel et bien une alternative pour la réduction sensible de l'importation et une opportunité pour l'économie de devises.

Attere $A$ and Fatokun, C, 1983. «Reaction of $O$. glaberrima accessions to yellow mottle virus», Plant Divers, (67), 420-421.

Baggie, I, Zapata, F., 2002 « Genotypic response to aluminium toxicity of somerice», Int. Rice Res. Notes, (27) 42.

Balasubramanian V, Sie M, Hijmans RJ, Otsuka K, 2007. Increasing rice production in sub-saharan Africa: Challenges and Opportunities. Advances, Agronomy Elsevier Inc. (94) 79

Bezançon G, 1993. Le riz cultivé d'origine africaine, Oryza glaberrima Steud. Et les formes sauvages et adventices apparentées : diversité, relations génétiques et domestication. Thèse de doctorat ès-sciences, Université de Paris-sud, Centre d'Orsay, pp. 19 et 23.

Bezançon G. et Diallo S, 2006. Oryza glaberrima Steud. [Internet] Fiche de Protabase. Brink M. \& Belay G. (Editeurs). PROTA (Plant Resources of Tropical Africa / Ressources végétales de I'Afrique tropicale), Wageningen, Pays Bas. http://database.prota.org/recherche.htm>. Visité en juin 2014.

Boeken GB, 1971. Etude agro-botanique des riz sauvages au Sénégal. Rome, PNUD/FAO; 87

Brydon L, 1981. " Rice, yams and chiefs in Avatime: speculations on the development of social order. Africa $\mathrm{N}^{\circ} 51,659-677$

Cantral R. and Reeves T, 2002. The cereal of the World's Poor takes center stage. Science, 296. 
Carney J, 2001. African rice in the columbian exchange. The Journal of African History, (42) 377-396.

Chandrasekhar U. and Mulk M, 1970. Nutritive value of High Yielding rice varieties Jaya, Padma and Hamsa. Indian, Journal of Nutrition and Dietetics, (7) 240-242.

Chang H, Yu B, Yu X, Yi L, Chen C, Mi M, and al, 2010. « Anti-cancer activities of an anthocyanin-rich extract from black rice against breast cancer cells in vitro and in vivo ». Nutrition and Cancer (62) (8) 1128-1136.

Courtois B, 1988, Les systèmes de culture du riz pluvial; Mémoires et Travaux de l'IRAT.

Dawe D, 2002. The changing structure of the world rice market, 1950-2000. Food Policy, (27) 355-70.

Defoer T, Wopereis MCS, Jones MP, Lançon F, Erenstein O, 2002. Challenges innovation and change: towards rice-based food security in subSaharan Africa. In proceedings of the 20th Session of the International Rice Commission. Bangkok-Thaillande.

Dingkuhn M, Johnson DE and al, 1999. «Relationship between upland rice canopy characteristics and weed competitiveness». Field Crops Res, (61) 79-95.

FAO, 2017. Suivi du Marché se Riz (SMR), Rapport, Vol $X X$, Ed 1, 10

Frei M. and Becker K, 2004. " Agro-biodiversity in subsistence-oriented farming systems in a Philippine upland region: nutritional considerations $»$. Biodiversity and Conservation (13) (8) 1591-1610.

Futakuchi K. and Sié M, 2009. Better Exploitation of African Rice (Oryza glaberrima Steud.) in Varietal Development for Resource-Poor Farmers in West and Central Africa. Agricultural Journal, (4) 96 - 102.

Gallais A. and Bannerot H, 1992. "Amélioration des espèces cultivées". INRA Paris Éditions, 71-88.

Gayin J, Chandi GK, Manful J, Seetharaman K, 2015. Classification of Rice Based on Statistical Analysis of Pasting Properties and Apparent Amylose Content: The Case of Oryza glaberrima accessions from Africa, Cereal Chem, (92) (1)22-28.

Jacquot M, Clement G, Guiderdoni E, Pons B, 1992. Le riz. In : Amélioration des espèces végétales cultivées, Gallais A.et Bannerot H. éd., Paris, France, INRA, 71-88; 118-119.

Jones MP. and Dingkuhn M, 1997. «Interspecific O. Sativa $\times 0$. glaberrima Steud. Progenies in upland rice improvement ». Euphytica, (92) 237246.

Juliano BO, Bautista GM, Lugay JC, Rey AC, 1964. Studies on the physico chemical properties of rice. Agricultural and Food Chemistry, (12), 131138.

Juliano BO. And Villareal CP, 1993. Grain Quality Evaluation of World Rices. International Rice Research Institute, Manilla Philippines, 205.

Juliano BO, 1994. Le riz dans la nutrition humaine. Rome, FAO - IRRI, $180 \mathrm{p}$.

Kiepe P, Diatta M, Millar, D, 2010. Innovation et partenariat pour atteindre le potentiel rizicole africain. Congrès du riz en Afrique. Banako, AfricaRice; 210.

Lai JH, 1995 « Rare black glutinous rice germplasm in eastern Guizhou province ». Crop Genetic Resources (2) 53-54.

Laignelet B, 1998. Le riz, in Godon, B.et Willm, C. Les industries de première transformation des céréales, Lavoisier. Tec et Doc/Apria. Paris: 7583,679

Lançon F. and Mendez del Villar P, 2012. Effets comparés des politiques publiques sur les marchés du riz et la sécurisation alimentaire en Afrique de I'Ouest: dépasser le débat libéralisation versus protection. Cahiers Agricultures- L'alimentation des villes, Étude originale, (21), 348-55

Lançon F, Erenstein O, Touré A, Akpokodje G, 2004. Qualité et compétitivité des riz locaux et importés sur les marchés urbains ouest-africains. Cahiers Agricultures. L'alimentation des villes, Étude originale (13), 110-5.

Laureys C.and Geeroms J, 2002. New insights in the unique characteristics of rice derivatives. Remy Industries N. V. Wijgmaal, 21

Maji T, Singh BN, Akenova ME, 2001. «Vegetative stage drought tolerance in 0 . glaberrima Steud and 0 . sativa $L$. and relationship between drought parameters». Oryza, (38), 17-23.

Megan S. and Mccouch S, 2007. The Complex History of the Domestication of Rice; Annals of Botany, 17.

Mendez Del Villar P. and Bauer JM, 2013. Le riz en Afrique de I'Ouest: dynamiques, politiques et perspectives. Cah Agric, 22, 336-44 doi : 10.1684/a9r.2013.0657.

Mendez del villar P, Bauer J, Maïga A, Laouali I, 2011. Crise rizicole, évolution des marchés et sécurité 
alimentaire en Afrique de l'Ouest. Rome: PAM; Cirad; CILSS; FAO; FEWS. www. wfp.org

Montcho D, Gbenou P, Missihoun AA, Futakuchi K, Ahanhanzo C, Agbangla C, 2017. Comparative study of two rice cultivars (Oryza glaberrima and 0 . sativa) under different cultural conditions. Journal of Experimental Biology and Agricultural Sciences; Volume - 5(1) http://www.jebas.org. ISSN No. 2320 - 8694

Montecinos GKL, Godoy JA, Carrillo Centeno PM, PachonH, 2011. "Sensory evaluation of the Azucena rice (Oryza sativa) variety in Nicaragua's Región Autónomadel Atlántico Norte ». Perspectivas en Nutrición Humana (13) (2) $135-146$.

Nayar NM, 2012. Évolution of the African Rice: A Historical and Biological Perspective. Crop Science Society of America (52) 505 - 516.

Ndjiondjop MN, Lorieux M, Sequier J, Fargette D, ReversatG, Second G, Ghesquiere A, 1996. Application des marqueurs moléculaires et de la cartographie génétique à l'utilisation du potentiel de l'espèce africaine de riz cultivé ( 0 .glaberrima Steud.) en amélioration des plantes. In Hybridations interspécifiques; ADRAO, Bouaké (Côte d'Ivoire). 123 - 139.

Ndjiondjop MN, Lalbar N. et al, 1999 «The genetic basis of high resistance to yellow mottle virus (RYMV) in cultivars of the two cultivated rice species», Plant Dis, (83) 22-24.

Nguetta ASP, Lidah JY, Ebélébé CNM, Guéi RG, 2006. Sélection de variétés performantes de riz pluvial (Oryza sp.) dans la région subéquatoriale $d u$ Congo Brazzaville, Afrique Science, 02 (3) 352 364

Nwilene FE, Williams UT. and al, 2002. «Reactions of differential genotypes to African gall midge in West Africa». Intel. Pest. Manag, (48) 195-201.

Obilana AB and Okumu BN, 2005. Evaluation Study Report For Inter specific Hybridization between African and Asian Rice Species. . African rice center (WARDA) Cotonou, Benin, pp: 81; http//www.warda.org/publications/UNDP \% 20 Report/ UNDP \%20 Report.

PAM, 2009. Analyse Globale de la Vulnérabilité à la Sécurité Alimentaire et Nutrition

Pearson SR, Stryker JD, Humphreys CP, 1981. Rice in West Africa: Policy and economics. Stanford (CA, USA) : Stanford University Press.

Pernes J, Berthaud J, Besançon G, Combes D, Leblanc JM, Lourd M, Savidan Y, Second G, 1984.
Gestion des ressources génétiques des plantes: monographies. Tome I. Edition Lavoisier. 212

Pham JL, 1992. Evaluation des ressources génétiques des riz cultivés en Afrique par hybridation intra et interspécifique. Thèse de Doctorat es sciences, Université de Paris XI ORSAY (France), 236.

Rodenburg J. and Johnson DE, 2009. Weed management in rice-Based cropping systems in Africa. Advance in Agronomy, (103) 150-201.

Romain HK, 2001. Agriculture en Afrique tropicale. Direction Générale de la Coopération Internationale, Ministère des Affaires étrangères, du Commerce Extérieur et de la Coopération Internationale, Bruxelles.

Sahrawat KL, 2004. «Iron toxicity in wetland rice and the role of other nutrients», J. Plant. Nutr, (27) 14711504.

Sahrawat KL, Mulback CK.1996. "The role of tolerant genotypes and plant nutrients in the management of iron toxicity in lowland rice». J. Agric. Sci. Cambridge, (126) 143-146.

Sarla N. and Swamy BPM, 2005. Oryza glaberrima: A source for the improvement of Oryza sativa, Current Science, (89) 25 955-963.

Seck PA, Tollens E, Wopereis MCS, Diagne A, Bamba I, 2010. Rising trends and variability of rice prices: Threats and opportunities for sub-Saharan Africa. Food Policy (35) 403-11.

Second G, 1984. Relations évolutives chez le genre Oryza et processus de domestication des riz. Thèse d'État, Orsay, Université Paris XI. Collection Études et thèses. ORSTOM, 189.

Sié $M, 2007$. Un pays où la recherche n'évolue pas, n'avance pas. Sidwaya, $n^{\circ} 5831$ du 21 février 2007, 17.

Sié M, Dogbé S. Diatta M, 2009. Sélection variétale participative du riz, Manuel du technicien. Centre du Riz pour l'Afrique; 126.

Sie M, Drame KN, Dakouo D, Traore K, Dogbe YD, Somado EA, Ogunbayo A, Semon M, Bamba I, Futakuchi K, Manneh B, Ndjiondjop MN, 2008.In conférence sur la biodiversité et amélioration génétique du riz en afrique subsaharienne. Agropolis International, Montpellier - France.

Sié M, 1991. Prospection et évaluation génétique des variétés traditionnelles de riz (Oryza sativa et 0. glaberrima Steud) du Burkina Faso. Thèse de Docteur - Ingénieur, spécialité: génétique et amélioration des espèces végétales, Faculté des Sciences et Techniques de I'Université Nationale de Côte d'Ivoire, Abidjan. 118 
Taguchi-shiobara F, Ozaki H, Sato H, Maeda H, Kojima $\mathrm{Y}$, Ebitani $\mathrm{T}$, et al, 2013. "Mapping and validation of QTLs for rice sheath blight resistance ». Breeding Science (63) (3) 301-308.

Thottapilly G. and Rossel HW, 1993. "Evaluation of resistance to rice yellow mottle virus in Oryza species». Indian virol, (9) 65-73.

USAID, 2009. Global food security response: West Africa rice value chain analysis. Washington (DC) United States Agency for International Development

USDA, 2013. Senegal: Grain and feed annual/2013 West Africa : Rice annual ». GAIN Report,

Vido AA, 2011. Le riz africain (Oryza glaberrima Steude), un aspect de l'histoire rurale de la Côte de l'Or ou l'extension de la zone de "civilisation du riz» (XVIlè-XVIIlè Siècles). Revue Ivoirienne d'histoire, $N^{\circ}$ 19, pp. 41 - 60.

Volvey A, Dévérin Y, Houssay-Holzschuch M, Rodarry E, Surun I, Bennafla K, 2005. L'ADRAO et le NERICA, « Riz Miracle Africain ». L'Afrique, coll. Clefs concours, Atlande, 288.

WARDA, 2004. Going beyond Upland NERICA: Another New Rice for Africa

WARDA, 2005. Vers des nouveaux horizons. Rapport annuel $2003-2004$.

Watanabe H, Futakuchi K, Jones MP et al, 2004. «Grain protein content of African rice (Oryza glaberrima Steud.) Lines and Asian rice (Oryza sativa L.) varieties in West Africa». Oryza, (41) 35-38.

Windmeijer PN, Duivenbooden NV, Andriesse W, 1994. Characterization of rice-growing agroecosystems in West Africa: semi-detailed characterization of inland valleys in Côte d'Ivoire. WARDA - Wageningen Agricultural University.

www.AfricaRice.org, visité en juillet 2015

Zoundi JS, Hitimana L, Hussein, 2005. Économie familiale et innovation agricole en Afrique de l'ouest : vers de nouveaux partenariats. SCSAO/SAH/D106. 